\title{
Substrate Integrated Waveguide (SIW) Bandpass Filter with Novel Microstrip-CPW- SIW Input Coupling
}

\author{
Augustine O. Nwajana, Amadu Dainkeh, Kenneth S. K. Yeo \\ Electrical and Electronic Engineering Department, University of East London, London E16 2RD, UK \\ a.nwajana@ieee.org,a.dainkeh@uel.ac.uk,k.yeo@uel.ac.uk
}

\begin{abstract}
A Substrate integrated waveguide bandpass filter is presented with a novel CPW-to-SIW transition at both the input and output ports which also served as the input and output couplings into the filter. The CPW-to-SIW transition structures presented here exploited the step impedance between the $50 \mathrm{ohms}$ input/output feedline and the transition to control the input/output couplings of the filter. The SIW filter is also shown to have very minimum milling or etching requirement which reduces the fabrication error. The proposed SIW filter has been validated experimentally and results presented. The results show that a simulated return loss of $15 \mathrm{~dB}$ and an initial measured return loss of $16 \mathrm{~dB}$ were achieved. An improved measured return loss of 22 dB was later achieved after some tuining adjustments were performed on the filter input and output couplings. A minimum insertion loss of $1.3 \mathrm{~dB}$ was also achieved across the band.
\end{abstract}

Index Terms - Bandpass filter, coplanar waveguide (CPW), coupling, substrate integrated waveguide (SIW).

\section{INTRODUCTION}

Substrate integrated waveguide (SIW) is a new type of transmission line that has evolved since the inception of the twenty-first century. This new technology has become popular in the past decade as it has opened new doors to the design of efficient microwave and millimetre-wave circuits at low cost. This new technology implements a conventional air-filled rectangular waveguide on a piece of printed circuit board (PCB) by replacing the side walls of the waveguide with two rows of metallic posts also known as via holes [1]. The SIW inherits the advantages of the microstrip, i.e. compact size and easy integration, but maintaining some of its waveguide characteristic, i.e. low radiation loss, high unloaded quality factor (Q-factor), as well as the high power handling characteristics. SIW as a transmission line is well established with details equations governing its physical structures, i.e. propagation mode, width of the transmission line and size of the metallic post, reported in [2].

Various authors have reported bandpass filters (BPFs) implemented with different transmission line technologies including: microstrip [3], waveguide [4], and SIW [5]. A BPF is a device that passes frequencies within a single band while rejecting all other frequencies outside the band [6], [7]. BPFs are crucial components in wireless communication systems to reject unwanted spectrum from the communication channels. Some design factors or parameters of filters such as selectivity, cost, size, 
sensitivity to environmental effects, power handling capacity, in-band and out-of-band performance metrics, are critical specifications when it comes to the development of radio frequency (RF) and microwave communication front ends. Designers are often required to make compromise between several conflicting requirements as it is rather difficult or even physically and/or electrically impossible to simultaneously achieve all design criteria or specifications. For instance, achieving higher channel selectivity usually requires the use of more resonators, which will result in higher insertion loss along the transmission path [8].

Transition between planar transmission lines and SIW structures are a vital element related to SIW devices [9]. A number of publications have presented SIW research findings with various types of input/output transitions. Microstrip-to-SIW transitions based on a simple taper have been presented in [10], [11]. The tapered section connects a 50 Ohms microstrip line and the SIW. The taper is used for transforming the quasi-TEM mode in the microstrip line into the $\mathrm{TE}_{10}$ mode in the SIW. Coplanar waveguide (CPW)-to-SIW transition based on a $90^{\circ}$ bend has also been proposed [12]. Another form of transition between a grounded coplanar waveguide (GCPW) and SIW based on a current probe was presented in [13]. The current flowing through the probe generates a magnetic field that matches with the magnetic field inside the SIW structure. Transitions between air-filled waveguide and SIW structure have also been presented [14], [15]. Microstrip-to-SIW transition in a multi-layer substrate have also been investigated and presented in [16]. The work presented in this paper employs a novel Microstirp-CPW-SIW transition as the input/output coupling to the filter's resonator. The proposed transition model makes it easy for RF and microwave designers to achieve controllable external Qfactor for filter design. The transition employs a step impedance from 50 Ohms microstrip to a low impedance GCPW before coupling into the filter using the short low impedance GCPW transmission line. This transition as an input/output coupling for filter is shown to be very efficient as it allows two degrees of freedom in controlling the input/output coupling, i.e. the input/output coupling or the external Q-factor can be varied by either changing the step impedance of the CPW or the length of the short CPW transmission line.

\section{SIW DESIGN}

Substrate integrated waveguide (SIW) is a planar transmission line with some inherited properties of rectangular waveguide as mentioned in the introduction. The physical structure of an SIW transmission line is shown in Fig. 1. The SIW transmission line itself consist of two metallic plates sandwiched by a dielectric material (dielectric substrate). Two rows of periodic metallic posts run along the length of the substrate to mimic the metallic sidewall of a rectangular waveguide. 


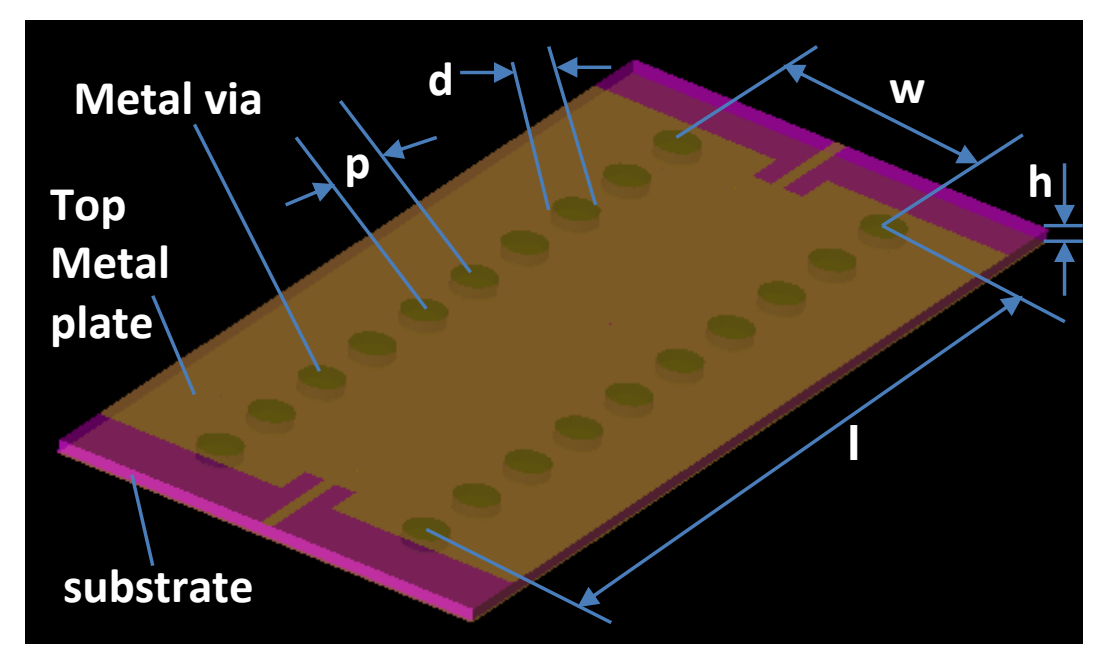

Fig. 1. Substrate integrated waveguide cavity.

To design a SIW transmission line to operate at a given frequency, there are three main design parameters that need to be considered. There are namely; the width of the SIW, w; the diameter of the metallic post, d; and the distance between the metallic posts (also commonly known as the pitch), p. The width of the SIW governs the cut-off frequencies of the propagation mode of the SIW transmission line in the same way as it does with width of the rectangular waveguide. The parameters, $\mathrm{d}$ and $\mathrm{p}$, determine how well the SIW transmission line mimics the rectangular waveguide itself. If $\mathrm{p}$ is reduced to $d / 2$, the SIW transmission line is effectively reduced to a dielectric filled rectangular waveguide. The larger $\mathrm{p}$ becomes the worst it diverges from a rectangular waveguide with electromagnetic energies leaking or radiating out between the metallic posts. According to a study in [17], for an electrically small metallic post, i.e. $d<0.2 \lambda$ where $\lambda$ is the wavelength of signal propagating in the dielectric material, the radiation loss is negligible when the ratio of $d / p$ is 0.5 . For a constant ratio of $\mathrm{d} / \mathrm{p}$, the radiation loss decreases as the size of the metallic post get smaller which is conditioned by the fabrication process [18]. It is important to note that the ratio $\mathrm{d} / \mathrm{p}$ is considered to be more critical than the values for $\mathrm{p}$ and $\mathrm{d}$ alone.

The size of an SIW cavity, for the fundamental $\mathrm{TE}_{101}$ mode, can be determined using the corresponding resonance frequency mode, $\mathrm{f}_{101}$ given in (1) [19] where $\mathrm{w}_{\text {eff }}$ and $l_{\text {eff }}$ are the effective width and length of the SIW cavity, $\mu_{\mathrm{r}}$ is the relative permeability (which is 1 for non-magnetic substrate) of the substrate, and $\mathrm{c}_{0}$ is the speed of light in free space. The empirical formulation for $\mathrm{w}_{\text {eff }}$ and $l_{\text {eff }}$ are given in (2) [1].

$$
\begin{gathered}
f_{101}=\frac{c_{0}}{2 \pi \sqrt{\mu_{r} \varepsilon_{r}}} \sqrt{\left(\frac{\pi}{w_{e f f}}\right)^{2}+\left(\frac{\pi}{l_{e f f}}\right)^{2}} \\
w_{e f f}=w-1.08 \frac{d^{2}}{p}+0.1 \frac{d^{2}}{w} ; \quad l_{\text {eff }}=l-1.08 \frac{d^{2}}{p}+0.1 \frac{d^{2}}{l}
\end{gathered}
$$




\section{BANDPASS FILTER CIRCUIT MODEL}

The test BPF reported in this paper was designed with the following specifications: center frequency $\mathrm{f}_{0}, 1684 \mathrm{MHz}$; fractional bandwidth FBW, 4\%; and passband return loss RL, $20 \mathrm{~dB}$. The BPF circuit model was designed based on the technique detailed in [18] and applied in [20]. As explained in [18], [20]; L, C and J are the inductance, capacitance and J-inverter values, respectively. The numerical design parameters for the BPF are shown in Table 1. The lossless circuit model with identical parallel LC resonators and J-inverters is shown in Fig. 2a. The BPF circuit model was simulated using the Agilent Advanced Design System (ADS) circuit simulator. The couplings between resonators were modelled using the method described in [18], i.e. modelling each J-inverter on the circuit model with a pi-network of capacitors. The simulation responses of the test BPF circuit model are shown in Fig. 2b.

TABLE I. 3-POLE CHEBYSHEV BANDPASS FILTER DESIGN PARAMETERS

\begin{tabular}{llllll}
\hline Filter & $\mathbf{f}_{\mathbf{0}}[\mathbf{M H z}]$ & $\mathbf{L}[\mathbf{n H}]$ & $\mathbf{C}[\mathbf{p F}]$ & $\mathbf{J}_{\mathbf{0 1}}$ & \\
\hline BPF & 1684 & 0.222 & 40.2424 & 0.02 & 0.0176 \\
\hline
\end{tabular}

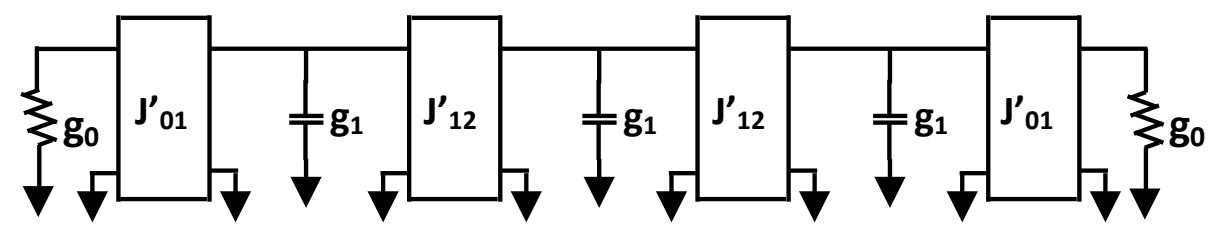

(a)

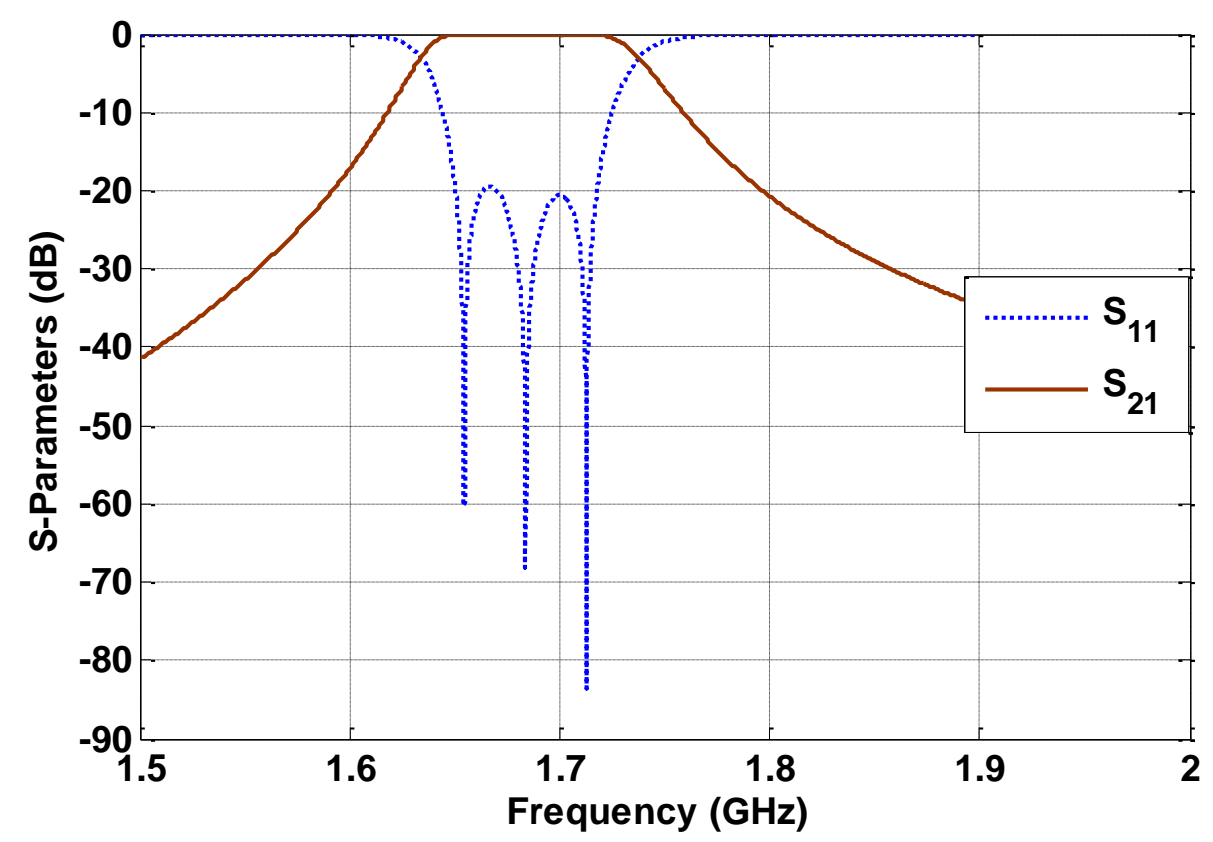

(b)

Fig. 2. 3-pole Chebyshev bandpass filter. (a) Circuit model with ideal LC resonators and J-inverters. (b) Simulation responses. 


\section{DESIGN AND SIMULATION}

The SIW cavity for the test BPF was designed to resonate at the $\mathrm{TE}_{101}$ mode resonance frequency, $\mathrm{f}_{0}$ of $1684 \mathrm{MHz}$ using (1). The filter was designed on a Rogers RT/Duroid 6010LM substrate with $\varepsilon_{\mathrm{r}}=$ $10.8, \mathrm{~h}=1.27 \mathrm{~mm}$ and $\mu_{\mathrm{r}}=1$. The SIW design parameters were chosen as follows: $\mathrm{d}=2 \mathrm{~mm}, \mathrm{p}=$ $3.725 \mathrm{~mm}, \mathrm{w}=37.25 \mathrm{~mm}$, and $l=37.25 \mathrm{~mm}$.

All electromagnetic (EM) simulations were carried out using the finite-element method (FEM) of the Keysight electromagnetic professional (EMPro) 3D simulator. A loss tangent, $\tan \delta=0.0023$ was assumed for the substrate, and a conductivity, $\sigma=5.8 \times 10^{7} \mathrm{~S} / \mathrm{m}$ for all the metals (copper) with 17 microns $(\mu \mathrm{m})$ thickness. In order to achieve faster simulation results convergence, each metallized via was implemented as an octadecagon (18 sided polygons).

The theoretical value of the coupling coefficient, $\mathrm{k}_{\mathrm{t}}$, for the filter was determined using (3), where FBW is the filter fractional bandwidth of $4 \% ; \mathrm{J}_{12}, \mathrm{~L}$, and $\mathrm{C}$ correspond to the values given in Table 1. The simulated value of the coupling coefficient, $k$, between each pair of SIW cavities were determined using the technique shown in Fig. 3 and using (4), where $\mathrm{f}_{1}$ and $\mathrm{f}_{2}$ are the Eigen-modes from simulating a pair of SIW cavities. The value of $\mathrm{k}$ that was used to achieve the test filter is $\mathrm{k}=$ 0.041 at $\mathrm{s}=13.05 \mathrm{~mm}$.

$$
\begin{gathered}
k_{t}=J_{12} \sqrt{\frac{L}{C}} \\
k=\frac{f_{2}^{2}-f_{1}^{2}}{f_{2}^{2}+f_{1}^{2}}
\end{gathered}
$$

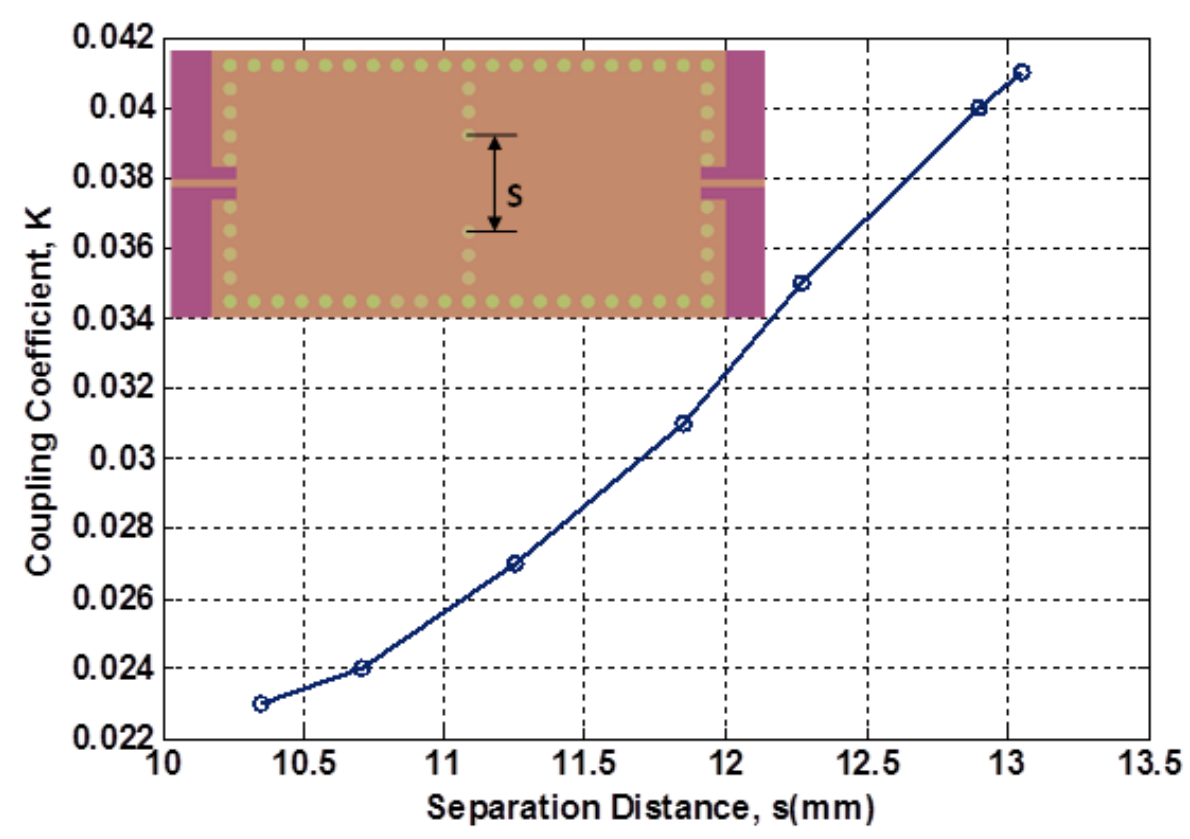

Fig. 3. Coupling coefficient of a pair of substrate integrated waveguide cavities. 
The theoretical external quality factor, $Q_{e x t}$, of the filter was extracted using (5), where $f_{0}, J_{0 l}$, and $C$ correspond to the values given in Table 1. Based on (5), the theoretical $Q_{e x t}$ value for the test SIW bandpass filter is 21.21. The simulated $Q_{e x t}$ value was based on the method shown in Fig. 4. The length corresponding to the $50 \mathrm{Ohms}$ impedance $\left(Z_{0}\right)$ of the microstrip transmission line was determined using the widely known formulations reported in [14]. The impedance $\left(Z_{1}\right)$, at the SIW end of the transition was achieved by adjusting the lengths, $a$ and $b$, until the required filter $Q_{e x t}$ value of 21.21 was achieved. A graph showing the variation of $Q_{e x t}$ with $a$, at constant $b$ (i.e. $b=8.13 \mathrm{~mm}$ ) is presented in Fig. 5a. Another graph showing the variation of $Q_{e x t}$ with $b$, at constant $a$ (i.e. $a=0.7$ $\mathrm{mm}$ ) is also presented in Fig. 5b. The value of $Z_{1}$ that corresponds to the required $Q_{e x t}$ value of 21.21 is $24 \mathrm{Ohms}$. This characteristic impedance value was worked-out by using the length, $y_{1}$ (from Fig. 6 and Table 2) and the widely known formulations reported in [18]. It is important to note that an increase in the length, $a$, would lead to an increase in the characteristic impedance, $Z_{1}$, and vice versa.

$$
Q_{\text {ext }}=\frac{2 \pi f_{0} C}{J_{01}}
$$

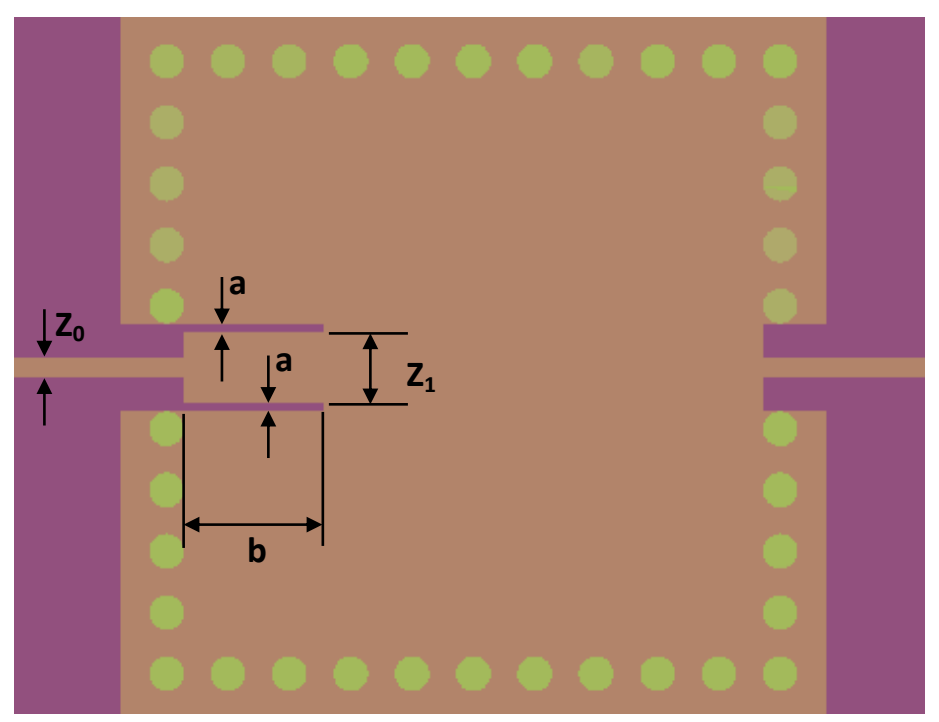

Fig. 4. Microstrip-CPW-SIW input coupling structure for extracting the external Q-factor.

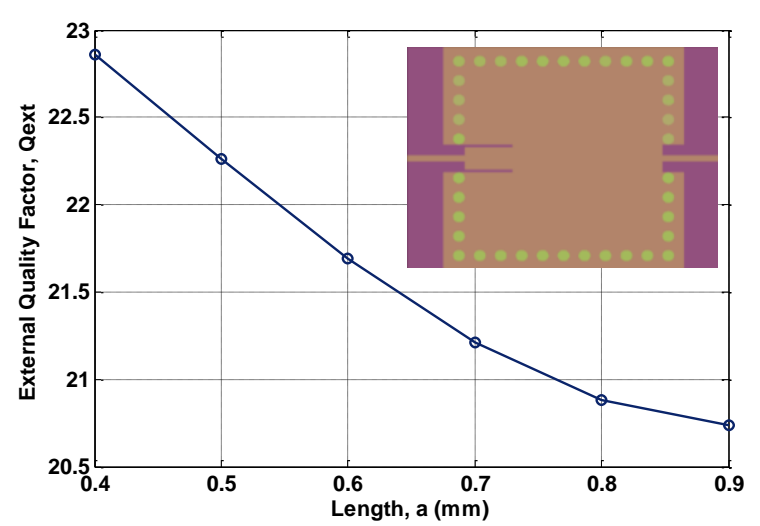

(a)

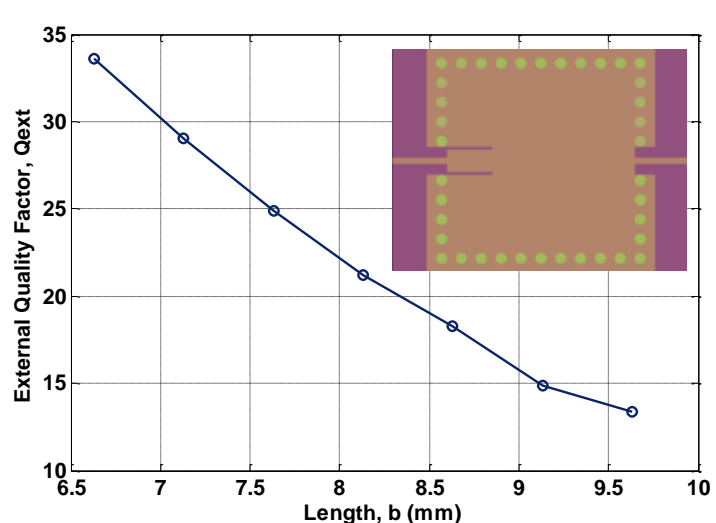

(b)

Fig. 5. Graphs for extracting the external Q-factor, $\mathrm{Q}_{\mathrm{ext}}$. (a) Variation of $\mathrm{Q}_{\mathrm{ext}}$, with length, a, at constant length, $\mathrm{b}=8.13 \mathrm{~mm}$. (b) Variation of $\mathrm{Q}_{\mathrm{ext}}$, with length, $\mathrm{b}$, at constant length, $\mathrm{a}=0.7 \mathrm{~mm}$. 
The complete FEM layout of the SIW BPF that was simulated using the Keysight EMPro 3D simulator is shown in Fig. 6, with all the physical dimensions for the filter shown in Table 2. The simulation responses of the proposed filter are presented in Fig. 7. It could be seen from the simulation results that the center frequency of the filter is about $1.68 \mathrm{GHz}$ as designed. A simulated minimum insertion loss $\left(\mathrm{S}_{21}\right)$ at the passband of $1.3 \mathrm{~dB}$ was achieved. The simulated return loss $\left(\mathrm{S}_{11}\right)$ is better than $14.6 \mathrm{~dB}$ across the passband. The filter passband is based on the fractional bandwidth specification and can be controlled by the input/output coupling and the couplings between each pair of SIW cavities. According to [17], [18]; the distance between neighbouring metal vias $p$ should be made equal or less than double the diameter of the metal via $d$ (i.e. $p \leq 2 d$ ) for best results. The larger the values of $\mathrm{p}$ and $\mathrm{b}$, the higher the electromagnetic leakage through the vias. This means higher radiation losses which negatively affect the filter insertion and return losses. The radiation loss becomes negligible at $p=2 d$ as explained in [17].

TABLE II. PHYSICAL DIMENSIONS OF THE SIW BANDPASS FILTER

\begin{tabular}{llll}
\hline Dimension & Value [mm] & Dimension & Value [mm] \\
\hline $\mathrm{x}_{1}$ & 8.125 & $\mathrm{y}_{1}$ & 3.9 \\
$\mathrm{x}_{2}$ & 37.25 & $\mathrm{y}_{2}$ & 0.7 \\
$\mathrm{x}_{3}$ & 111.75 & $\mathrm{y}_{3}$ & 1.1 \\
$\mathrm{~d}$ & 2.0 & $\mathrm{y}_{4}$ & 37.25 \\
$\mathrm{p}$ & 3.725 & $\mathrm{~s}_{1}$ & 13.05 \\
\hline
\end{tabular}

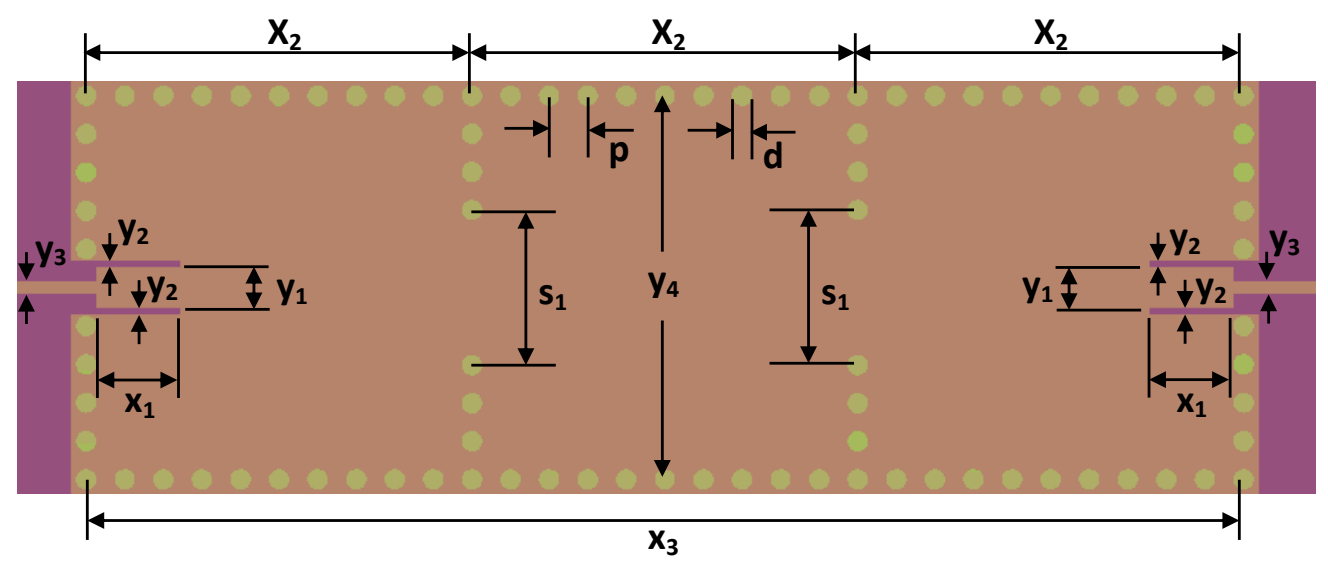

Fig. 6. Substrate integrated waveguide bandpass filter layout with dimensions. 


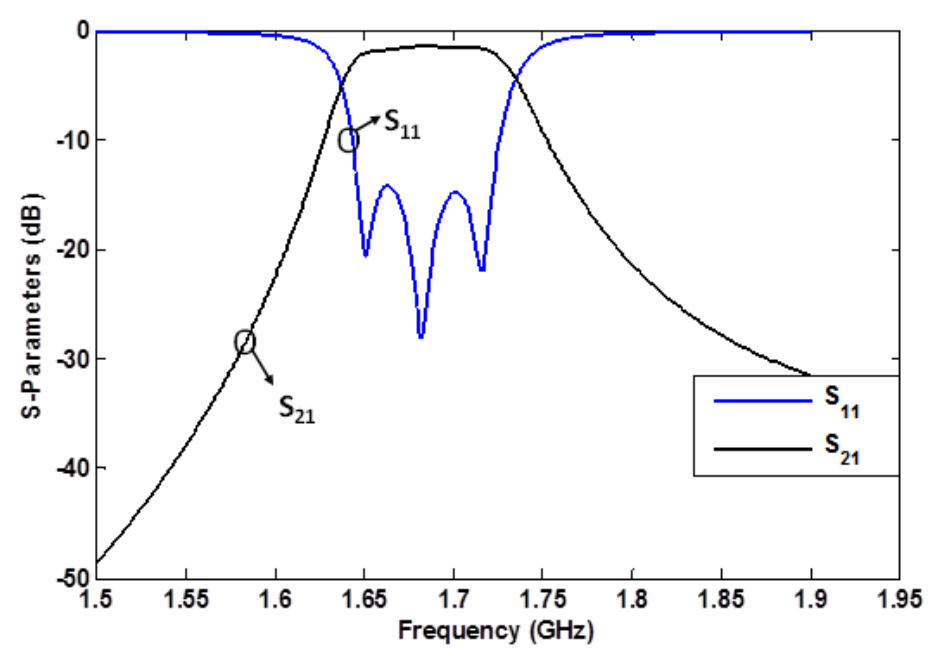

Fig. 7. Simulation responses of the substrate integrated waveguide bandpass filter.

\section{FABRICATION AND MEASUREMENT}

The SIW bandpass filter was fabricated using the same material employed in the FEM simulation. The fabrication was based on printed circuit board (PCB) micro-milling process using the "Leiterplatten-Kopierfräsen" (LKPF) Protomat C60. The photograph of the fabricated filter is shown in Fig. 8. In order to facilitate measurement of the filter, two SMA (Sub-Miniature version A) connectors were fitted onto the input and output ports as shown. The fabricated filter was measured using the Agilent Vector Network Analyzer. Fig. 9 shows the measured results indicating that a minimum insertion loss $\left(\mathrm{S}_{21}\right)$ of $1.3 \mathrm{~dB}$ was achieved at the passband. The minimum simulated and initial measured return losses $\left(\mathrm{S}_{11}\right)$ of $15 \mathrm{~dB}$ and $16 \mathrm{~dB}$ were respectively achieved across the passband. An improved measured return loss of better than $22 \mathrm{~dB}$ across the passband was later achieved after some tuning adjustments were made at the input/output couplings. The improved return loss is shown in Fig. 9b. The measurement and simulation results are jointly presented in Fig. 10 for ease of comparison. It is clear from Fig. 10 that the simulation and the initial measurement results are in good agreement. The improved measured return loss of $22 \mathrm{~dB}$ shown in Fig. 10 was achieved by tuining the filter input and output couplings, while viewing the responses on a vector network analyzer. The electrical size of the bandpass filter reported in this paper is $0.21 \lambda_{\mathrm{g}} \times 0.63 \lambda_{\mathrm{g}}$ which is more compact than the waveguide filter reported in [4], but less compact when compared to the microstrip filter reported in [3]. In general, SIW filters are normally smaller in size when compared to waveguide filters, but are relatively larger in size when compared to microstrip filters. The return loss of the filter reported in this paper is slightly better than that reported in page 2569 of [4] where the measured return loss is about $11 \mathrm{~dB}$, as opposed to the minimum measured return loss of $16 \mathrm{~dB}$ achievd here. The roll-off factor and band rejection of our simulated and measured results are very steepy and in good agreement when compared to that of the filter presented in [4]. 


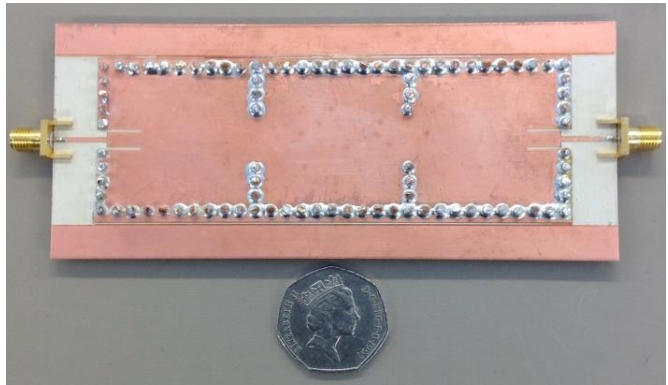

(a)

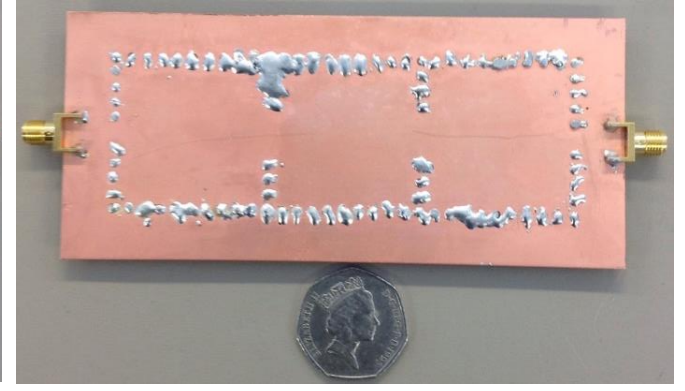

(b)

Fig. 8. Fabricated SIW bandpass filter photograph. (a) Top view. (b) Bottom view.

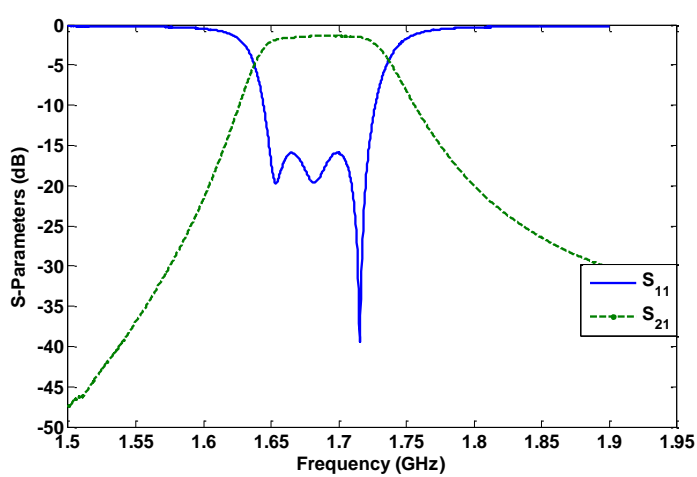

(a)

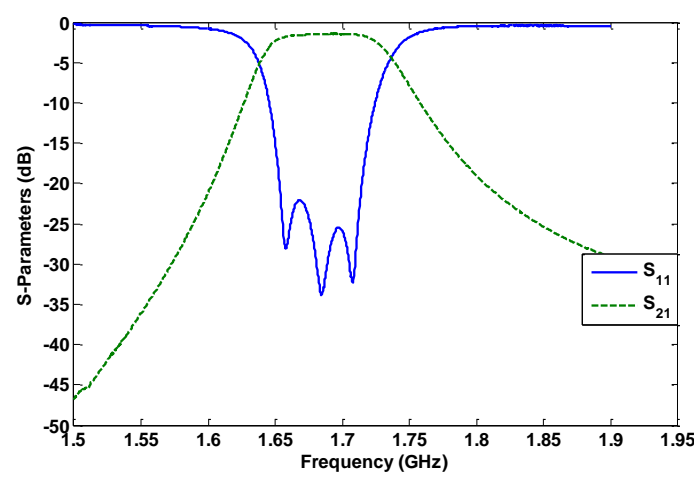

(b)

Fig. 9. Measurement results of the SIW bandpass filter. (a) Without tuning. (b) After tuning.

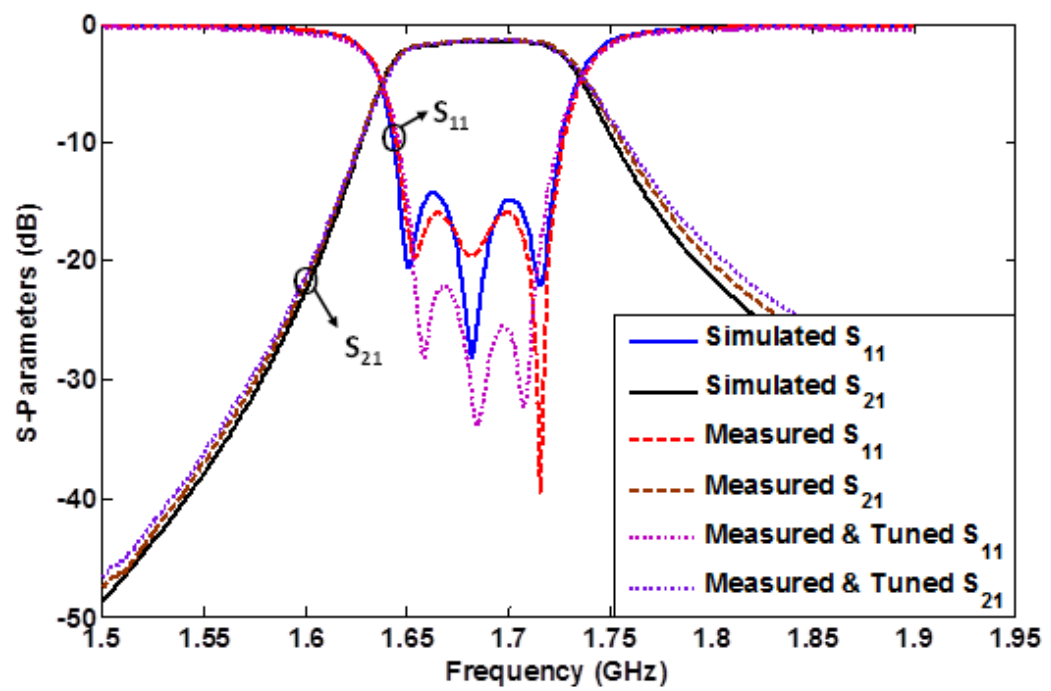

Fig. 10. Comparison of the simulated and measured results of the filter.

\section{CONCLUSION}

A substrate integrated waveguide bandpass filter with a new type of Microstrip-CPW- SIW input coupling has been presented. The proposed filter has been designed, simulated, manufactured and 
measured. The Microstrip-CPW-SIW transition employed as the input coupling in the design allows two degrees of freedom in controlling the external Q-factor. Stepping the 50 Ohms feedline impedance to a lower impedance at the SIW end of the transition makes it easier to realize the required filter external quality factor, $Q_{\text {ext }}$. Changing the impedance at the SIW end of the transition, changes the $\mathrm{Q}_{\mathrm{ext}}$. The experimentally verified results show that a minimum insertion loss of $1.3 \mathrm{~dB}$ was achieved across the band. An initial measured minimum return loss of $16 \mathrm{~dB}$ was achieved before any tuning was performed on the input/output ports. With some tuning on the filter input and output couplings, a slight improvement of return loss was achieved with a measured minimum of $22 \mathrm{~dB}$. The results presented show that there is a good agreement between the simulated and measured filter responses. Due to the minimum milling/etching of this particular design, a very good agreement between simulation and raw experimental results was achieved.

\section{REFERENCES}

[1] S. H. Han, X. L. Wang, Y. Fan, Z. Q. Yang, and Z. N. He, "The generalized Chebyshev substrate integrated waveguide diplexer," Progress in Electromagnetic Research, vol. 73, pp. 29-38, 2007.

[2] D. Deslandes, and K. Wu, "Accurate modelling, wave mechanisms, and design considerations of a substrate integrated waveguide" IEEE Trans. Microw. Theory and Techn., vol. 56, no. 6, pp. 2516-2526, Jun. 2006.

[3] C.-F. Chen, S.-F. Chang, and B.-H. Tseng, "Design of compact microstrip sept-band bandpass filter with flexible passband allocation," IEEE Microw. Wireless Compon. Lett., vol. 26, no. 5, pp. 346-348, May 2016.

[4] N. Mohottige, O. Glubokov, U. Jankovic, and D. Budimir, "Ultra compact inline E-plane waveguide bandpass filter using cross coupling," IEEE Trans. Microw. Theory and Techn., vol. 64, no. 8, pp. 2561-2571, Aug. 2016.

[5] A. Rhbanou, M. Sabbane, and S. Bri, "Design of K-band substrate integrated waveguide band-pass filter with high rejection," J. of Microw., Optoelectronics and Electromagnetic Applications, vol. 14, no. 2, pp. 155-169, Dec. 2015.

[6] A. O. Nwajana and K. S. K. Yeo, "Microwave diplexer purely based on direct synchronous and asynchronous coupling," Radioengineering, vol. 25, no. 2, pp. 247-252, Jun. 2016.

[7] A. O. Nwajana and K. S. K. Yeo, "Multi-coupled resonator microwave diplexer with high isolation," in Proc. 46th Eur. Microw. Conf., IEEE, Oct. 2016, pp. 1167-1170.

[8] X.-P. Chen and K. Wu, "Substrate integrated waveguide filter: basic design rules and fundamental structure features," IEEE Microw. Mag., vol. 15, no. 5, pp. 108-116, Jul. 2014.

[9] M. Bozzi, A. Georgiadis, and K. Wu, "Review of substrate-integrated waveguide circuits and antennas," IET Microw., Antennas \& Propagation, vol. 5, no. 8, pp. 909-920, Jun. 2011.

[10] D. Deslandes and K. Wu, "Integrated microstrip and rectangular waveguide in planar form," IEEE Microw. Wireless Compon. Lett., vol. 11, no. 2, pp. 68-70, Feb. 2001.

[11] D. Deslandes, "Design equations for tapered microstrip-to-Substrate Integrated Waveguide transitions," IEEE MTT-S Int. Microw. Symp. Dig., May. 2010, pp. 704-707.

[12] D. Deslandes and K. Wu, "Integrated transition of coplanar to rectangular waveguides," IEEE MTT-S Int. Microw. Symp. Dig., vol. 2, May 2001, pp. 619-622.

[13] D. Deslandes and $\mathrm{K}$. Wu, "Analysis and design of current probe transition from grounded coplanar to substrate integrated rectangular waveguides," IEEE Trans. Microw. Theory and Techn., vol. 53, no. 8, pp. 2487-2494, Aug. 2005.

[14] Y. Huang and K. L. Wu, "A broad-band LTCC integrated transition of laminated waveguide to air-filled waveguide for millimeter-wave applications," IEEE Trans. Microw. Theory and Techn., vol. 51, no. 5, pp. 1613-1617, May 2003.

[15] L. Xia, R. Xu, B. Yan, J. Li, Y. Guo, and J. Wang, "Broadband transition between air-filled waveguide and substrate integrated waveguide," IET Electron. Lett., vol. 42, no. 24, pp. 1403-1405, Nov. 2006.

[16] Y. Ding and K. Wu, "Substrate integrated waveguide-to-microstrip transition in multilayer substrate," IEEE Trans. Microw. Theory and Techn., vol. 55, no. 12, pp. 2839-2844, Dec. 2007.

[17] D. Deslandes and K. Wu, "Single-substrate integration technique of planar circuits and waveguide filters," IEEE Trans. Microw. Theory and Techn., vol. 51, no. 2, pp. 593-596, Feb. 2003.

[18] J.-S. Hong, Microstrip Filters for RF/Microwave Applications. New York, NY, USA: 2011.

[19] X. Chen, W. Hong, T. Cui, J. Chen, and K. Wu, "Substrate integrated waveguide (SIW) linear phase filter," IEEE Microw. Wireless Compon. Lett., vol. 15, no. 11, pp. 787-789, Nov. 2005.

[20] K. S. K. Yeo and A. O. Nwajana, "A novel microstrip dual-band bandpass filter using dual-mode square patch resonators," Progress in Electromagnetic Research C, vol. 36, pp. 233-247, 2013. 